\title{
Rare Case of a Patient Presenting with Parathyroid Hormone-Related Peptide Mediated Hypercalcemia and IgG Heavy Chain Disease: Case Report and Review of Literature
}

\author{
Damien Hansra ${ }^{1}$, Diaz Liege ${ }^{2}$, Victoria Sujoy ${ }^{3}$, Ikpatt Offiong ${ }^{3}$, Chris Wunsch ${ }^{3}$, \\ James E. Hoffman" \\ ${ }^{1}$ Oncology and Radiation Associates, Miami, USA \\ ${ }^{2}$ Department of Internal Medicine, University of Miami/Jackson Memorial Hospital, Miami, USA \\ ${ }^{3}$ Department of Pathology and Laboratory Medicine, University of Miami/Jackson Memorial Hospital, Miami, \\ USA \\ ${ }^{4}$ Sylvester Comprehensive Cancer Center, Miami, USA \\ Email: ${ }^{*}$ dmhansra@gmail.com
}

Received 6 August 2015; accepted 13 September 2015; published 16 September 2015

Copyright $(\subset 2015$ by authors and Scientific Research Publishing Inc.

This work is licensed under the Creative Commons Attribution International License (CC BY). http://creativecommons.org/licenses/by/4.0/

(c) (i) 0 pen Access

\section{Abstract}

IgG Heavy Chain Disease ( $\gamma \mathrm{HCD}$ ) is a rare plasma cell disorder. Hypercalcemia related to plasma cell dyscrasias is related to non-PTHrP related mechanisms. Here we describe the first case of a patient with $\gamma \mathrm{HCD}$ and PTHrP related hypercalcemia. Methods: Patient case derived from chart review from 2011 to 2015. Literature review performed searching PubMed 1968-current. Results: The patient was diagnosed with hypercalcemia with elevated PTHrP and exclusion of other etiologies of hypercalcemia. She was diagnosed with $(\gamma \mathrm{HCD})$ by M-spike $0.64 \mathrm{~g} / \mathrm{dL}$, IFE showing a broad band of IgG heavy chain, without associated light chains and severe depression of the non-monoclonal IgG. Serum immunoglobulins demonstrated elevated IgG $(2110 \mathrm{mg} / \mathrm{dL})$, normal IgA (46 $\mathrm{mg} / \mathrm{dL}$ ) and decreased IgM ( $<21 \mathrm{mg} / \mathrm{dL})$. Bone marrow biopsy showed $5 \%$ PCs, non-clonal by kappa/lambda, but exclusive for IgG by IHC, without any staining for IgA or IgM. The patient was started on therapy with improved hypercalcemia and PTHrP levels. Conclusions: This is the first reported case of $\gamma \mathrm{HCD}$ presenting with PTHrP related hypercalcemia. Given that skeletal involvement is uncommon in $\gamma \mathrm{HCD}$, hypercalcemia secondary to $\gamma \mathrm{HCD}$ may at times be a PTHrP driven phenomenon and we recommend that this test be ordered in such cases.

\footnotetext{
${ }^{*}$ Corresponding author.
} 


\section{Keywords}

\section{Hypercalcemia, Parathyroid Hormone-Related Peptide (PTHrP), Franklin Disease, Heavy Chain Myeloma}

\section{Background}

IgG Heavy Chain Disease ( $\gamma \mathrm{HCD}$ ) is a rare and often lymphoplasmacytic neoplasm that produces an abnormally truncated gamma heavy chain protein that lacks associated light chains [1]. It is a heterogeneous entity that occurs within a wide spectrum of lymphoproliferative disorders. Consequently, $\gamma \mathrm{HCD}$ displays a wide range of clinicopathologic characteristics. Here we describe a unique case of a patient diagnosed with Hodgkin's lymphoma and diagnosed several years later with $\gamma \mathrm{HCD}$ who presents with PTHrP related hypercalcemia.

\section{Methods}

A retrospective chart review of one patient from 2011 to 2015 including detailed clinical history, laboratory data, imaging, pathology and treatment response was performed. PubMed, EMBASE and the Cochrane Library databases were searched for English language abstracts that included mesh terms "IgG Heavy Chain Disease" or "franklin disease" from 1968-current. 79 abstracts were retrieved. 38/79 abstracts were available for review of clinicopathologic information.

\section{Results}

This is a case of a 60-year-old woman diagnosed in 1992 with stage IIA Hodgkin's lymphoma, treated with total nodal radiation with recurrence in 1997 then treated with 6 cycles of ABVD achieving complete remission. On March 2011 the patient was then found to have hypercalcemia $(11.0 \mathrm{mg} / \mathrm{dL})$ and renal failure $(1.29 \mathrm{mg} / \mathrm{dL})$. Workup for the hypercalcemia revealed suppressed PTH $(<3 \mathrm{pg} / \mathrm{ml})$, elevated ionized calcium $(6.1 \mathrm{mg} / \mathrm{dL})$ elevated parathyroid related peptide $(38 \mathrm{pg} / \mathrm{ml})$, normal vitamin D and ACE levels. Complete blood count was normal. Serum protein electrophoresis (SPEP) showed M-spike of $0.9 \mathrm{~g} / \mathrm{dL}$. Immunofixation electrophoresis (IFE) demonstrated an IgG monoclonal immunoglobulin without a corresponding light chain (Figure 1). Free serum kappa and lamda light chains were within normal limits. Serum IgG was elevated $(4678 \mathrm{mg} / \mathrm{dL})$ with

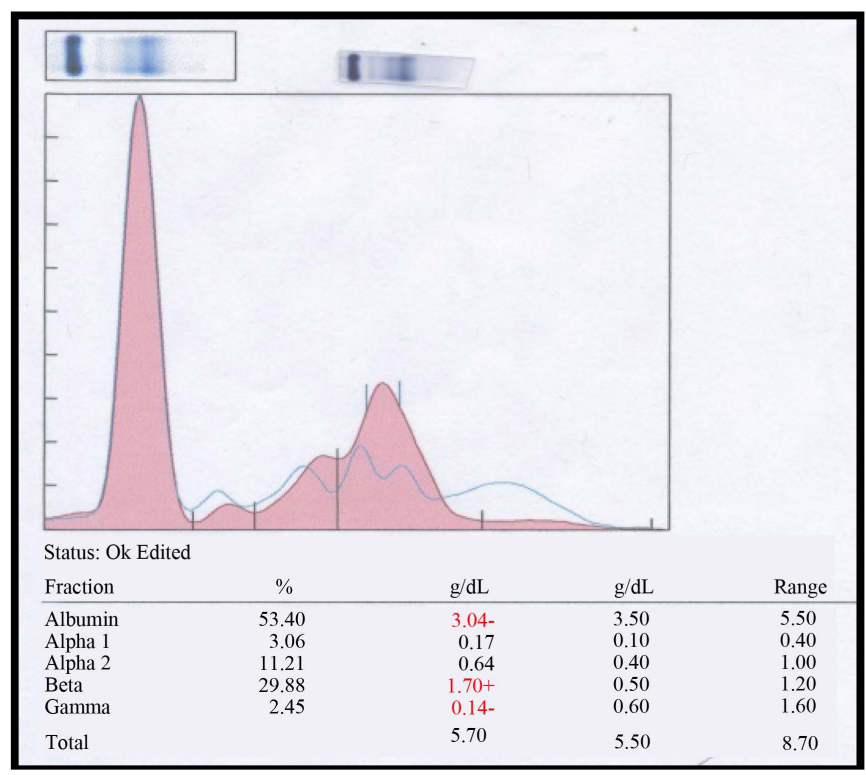

Figure 1. SPEP demonstrating M-spike. The blue trace shows a normal SPEP pattern. 
normal IgA (127 mg/dL), and low IgM (39 mg/dL). Beta-2 microglobulin was elevated $(14.3 \mathrm{mg} / \mathrm{L})$ also. The patient was seen by hematology for monoclonal gammopathy and hypercalcemia. Since the most common mechanism of hypercalcemia for multiple myeloma is bone turnover driven and not PTHrP related a solid tumor work up was done including CT chest/abdomen/pelvis, bone scan, bone survey, mammography, pelvis ultrasound which were all negative. Bone marrow biopsy was performed in November 2011 showing $10 \%$ plasma cells (PC) by CD138, non-clonal by kappa/lambda staining. Despite zolendonic acid therapy and IV fluids for hypercalcemia, her renal function and hypercalcemia continued to worsen for the next couple of months. A kidney biopsy was performed in April, 2012 and revealed acute and chronic tubulointerstitial nephritis with secondary glomerulosclerosis, mild interstitial fibrosis and tubular atrophy suggestive of sarcoidosis so the patient was placed on a course of prednisone with transient improvement in calcium and renal function but patient lost to follow up.

She presented in emergency room in April 2013 with altered mental status. She was found to have hypercalcemia $(12.0 \mathrm{mg} / \mathrm{dL})$, renal failure $(1.55 \mathrm{mg} / \mathrm{dL})$. SPEP revealed M-spike $0.64 \mathrm{~g} / \mathrm{dl}$. IFE displayed a broad band of IgG heavy chain, without associated light chains and severe depression of the non-monoclonal IgG. Serum immunoglobulins demonstrated similar results with elevated $\operatorname{IgG}(2110 \mathrm{mg} / \mathrm{dL})$, normal $\mathrm{IgA}(46 \mathrm{mg} / \mathrm{dL})$ and decreased IgM $(<21 \mathrm{mg} / \mathrm{dL}$ ). Bone marrow biopsy showed 5\% PCs (Figure 2), CD 138 positive by IHC (Figure 3), non-clonal by kappa/lambda-but exclusive for IgG by IHC, without any staining for IgA or IgM (Figure 4). Cytogenetics were normal. Based on the constellation of findings and similarity to prior workup the patient was diagnosed with $\operatorname{IgG}$ heavy chain disease. She received 5 cycles of cytoxan, dexamethasone, bortezomib. PTHrP declined along with her IgG level and M-spike. Due to compliance issues, therapy was changed in multiple occasions receiving Revlimid, Carfilzomib, Bendmustine with different responses as showed in Table 1.

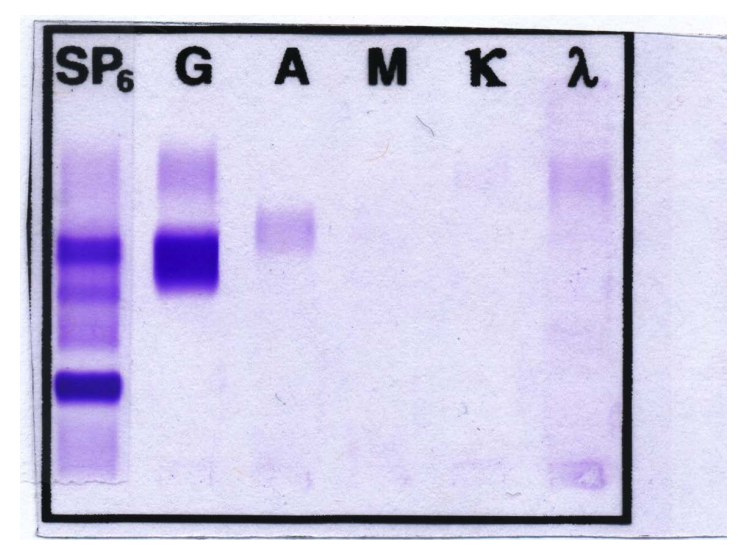

Figure 2. IFE demonstrating monoclonal IgG without corresponding light chain.

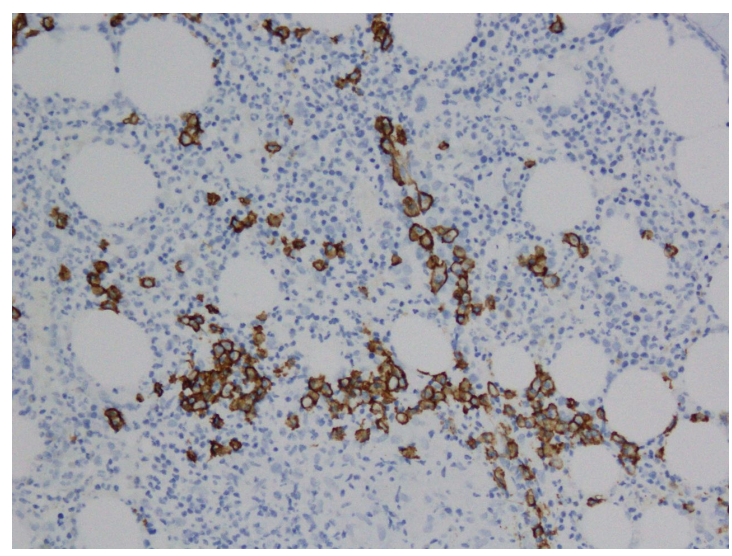

Figure 3. Bone marrow biopsy $200 \times, \mathrm{CD} 138+$ plasma cells arranged in an interstitial and perivascular pattern. 


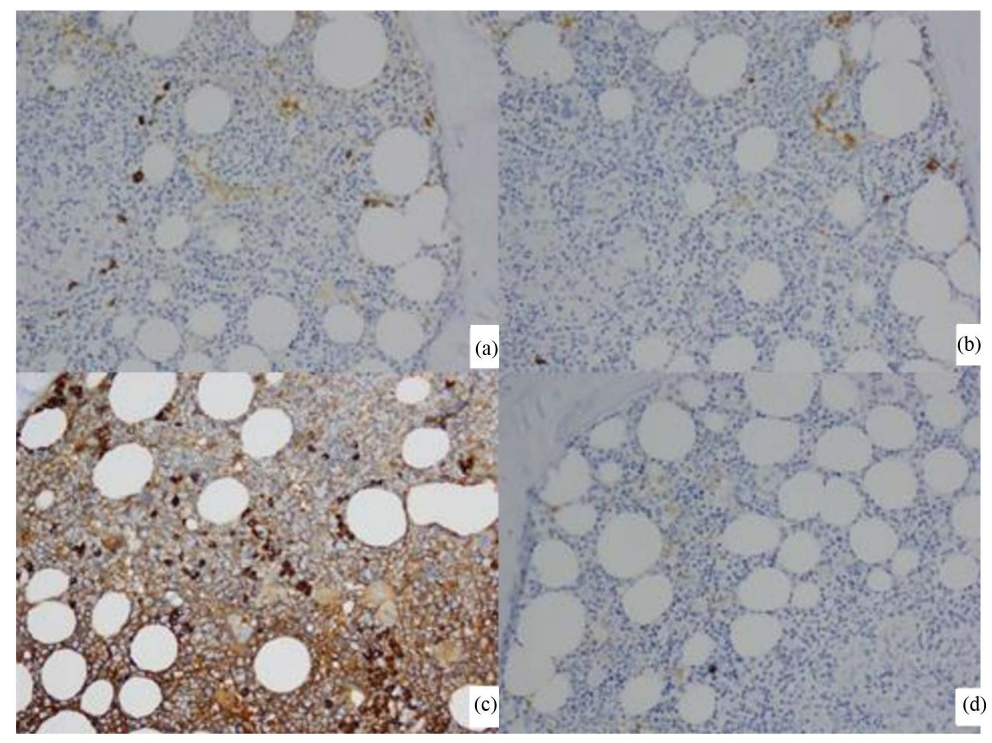

Figure 4. (a) $200 \times$, few plasma cells positive for kappa light chain by immunohistochemistry. (b) $200 \times$, few plasma cells positive for lambda light chain by immunohistochemistry. (c) $200 \times$, majority of the plasma cells show positive staining for IgG by immunohistochemistry. (d) $200 \times$, plasma cells are negative for IgM by immunohistochemistry.

Table 1. Treatments and responses.

\begin{tabular}{|c|c|c|c|c|c|c|c|c|c|c|c|c|}
\hline Day & $6 / 27 / 11$ & $5 / 14 / 13$ & $6 / 12 / 13$ & $12 / 04 / 13$ & $1 / 29 / 14$ & $2 / 24 / 14$ & $3 / 5 / 14$ & $7 / 23 / 14$ & $1 / 28 / 15$ & $2 / 15 / 2015$ & $3 / 18 / 15$ & $7 / 1 / 15$ \\
\hline Treatment & Observation & $\begin{array}{l}\text { Observation } \\
\text { Worsening } \\
\text { renal } \\
\text { function. }\end{array}$ & $\begin{array}{l}\text { After } 1^{\text {st }} \\
\text { cycle } \\
\text { cyBORd }\end{array}$ & $\begin{array}{c}\text { After last } 5^{\text {th }} \\
\text { cycle of } \\
\text { cyBORd }^{1}\end{array}$ & $\begin{array}{l}\text { Started on } \\
\text { Revlimid }\end{array}$ & $\begin{array}{c}\text { On } \\
\text { Revlimid }^{2}\end{array}$ & $\begin{array}{l}\text { Started on } \\
\text { Carfilzomib }\end{array}$ & $\begin{array}{c}\text { On } \\
\text { Carfilzomib }^{3}\end{array}$ & $\begin{array}{l}\text { Not on } \\
\text { therapy }\end{array}$ & $\begin{array}{c}\text { Started on } \\
\text { Bendamustine } \\
\text { due to } \\
\text { increasing } \\
\text { IgG }\end{array}$ & $\begin{array}{c}\text { On } \\
\text { Bendamustine }\end{array}$ & $\begin{array}{c}\text { Not on } \\
\text { treatment } \\
\text { since march } \\
2015 .\end{array}$ \\
\hline IgG levels & 4678 & 2470 & 1650 & 1570 & 1930 & 1900 & 1080 & 1040 & 2180 & N/A & 1760 & 2360 \\
\hline
\end{tabular}

${ }^{1}$ CyBORd: velcade-cytoxan-dexametasone. Discontinued due to noncompliance. ${ }^{2}$ Revlimid discontinued due to patient noncompliance. ${ }^{3}$ Received 6 months of Carfizomib and then discontinued on 12/2014 due to side effects. ${ }^{4}$ Bendamustine stopped per patient request on March 2015 . Not further treatment.

\section{Discussion}

The clonal disease underlying Gamma heavy-chain disease $(\gamma \mathrm{HCD})$ is heterogeneous mix, including a wide spectrum of lymphoproliferative disorders. Most cases are described as a neoplasm of lymphocytes and plasma cells similar to lymphoplasmacytic lymphoma (LPL) [1] [2] however $\gamma \mathrm{HCD}$ has been reported in association with marginal zone lymphoma [1], T cell LGL, [3], monoclonal gammopathy of unknown significance [1] [4] [5], plasmacytoma [1] [4] [6] [7], Waldenström's macroglobulinemia [4] [8], Hodgkin lymphoma [1] [4] [9], chronic lymphocytic leukemia (CLL) [4] [9]. In addition to arising in the setting of a lymphoproliferative neoplasm, patients frequently have a pre-existing autoimmune disorder such as rheumatoid arthritis [1] [4] [9] [10] [11], Sjögren's syndrome [4] [12], systemic lupus erythematosus [1] [4] [9]. Patients with $\gamma \mathrm{HCD}$ can present with various clinical and pathologic features, which usually precede the diagnosis of $\gamma \mathrm{HCD}$.

\subsection{Clinical Presentation}

$\gamma \mathrm{HCD}$ occurs equally in males in females. One case series by Fermand et al. reported 8/16 (50\%) of patient to be female and they cite in literature review $47 \%$ female predominance. Two more recent series, however, report female predominance. In one series $11 / 13(85 \%)$ were female [1] and 15/23 (65\%) were female in another series [9]. Patients with $\gamma \mathrm{HCD}$ are predominantly middle aged. Median age at diagnosis reported in largest case series ranges $59[1]$ to 68 [9] and $\gamma \mathrm{HCD}$ can occur in younger patients as there are 6 reports in children and adults less than 20 years old [4]. At diagnosis lymphadenopathy is present $34 \%$ to $61 \%$ of patient [1] [4] [9]. Splenomegaly is also common feature with $30 \%$ to $75 \%$ patient affected [1] [4] [9]. There is a variety of different extranodal sites with reported involvement including thyroid [2] [4] [6] [7] [9], renal [2] [13]-[17] skin [14] [18], skeletal 
muscle [16], stomach [19], submaxillary gland [20], tongue [9], vocal cord [9], lung and pleura [9], and parotid gland involvement [21].

\subsection{Associated Disorders}

Autoimmune disorders are common in $\gamma \mathrm{HCD}$ with one literature review reporting $26 \%$ of patients with $\gamma \mathrm{HCD}$ having autoimmune disorder [4]. Rheumatoid arthritis is the most commonly reported [4] [10] [11]. Other autoimmune diseases reported include Sjögren's syndrome [12], systemic lupus erythematosus [1], vasculitis [4], livedo reticularis [1], thyroiditis [4] myasthenia gravis [22], idiopathic thrombocytopenic purpura [4]. Numerous reports exist of $\gamma \mathrm{HCD}$ occurring in the setting of infection such as progressive multifocal leukoencephalopathy [23], pachymeningitis [24], herpes zoster [9] disseminated herpes simplex [9], crytococcal meningitis [9], orbital cellulitis [29]. Infections were not exclusive to patients treated with immunosuppressive agents for autoimmune disorders. Last, $\gamma \mathrm{HCD}$ patients have been described in the setting of neurosensory dysfunction including polyneuropathy and peripheral neuropathy [4].

\subsection{Laboratory Findings}

Anemia is a common finding with one series reporting 9/16 (56\%) patients being anemic [4] and a literature review showed $48 \%$ of patients reported to be anemic [4]. Coombs positive autoimmune hemolytic anemia [9] [25] has been reported with one series demonstrating $2 / 23$ (9\%) patients with a positive coombs [9]. Leukocyte count is frequently normal [4] [9] but leukocytosis and leukopenia can occur as well [4] [9]. Eosinophilia was present in 8/16 (50\%) in one series [4] and 4/23 (17\%) in another [9]. Thrombocytopenia is present in 4/23 (17\%) in one series [9], and 4/16 (25\%) in another series [9]. Hypocomplimentenemia was noted in one case [14]. Hypercalcemia has been reported in several cases [4] [9] [26]. In a literature review, hypercalcemia was reported in 5 cases with osteolytic lesions diagnosed in 2 [4]. Hypercalcemia was noted in $2 / 23(9 \%)$ of cases in one series [9] and there were no mention of osseous lesions in the individual reports. Of note the incidence of osseous lesions is low $\gamma \mathrm{HCD}$ with one series reporting $0 / 5(0 \%)$ and another 2/12 (17\%) with bony involvement [4] [9]. Based on these observations, hypercalcemia in $\gamma \mathrm{HCD}$ may less often be osteoclast driven as in multiple myeloma, and perhaps other mechanisms are in play

\subsection{Pathologic Characteristics}

Pathologic diagnosis of $\gamma \mathrm{HCD}$ represents a challenge for many reasons. First $\gamma \mathrm{HCD}$ may be underdiagnosed and classified elsewhere since it arises in the setting of many lymphoproliferative disorders with specific WHO criteria. Also, $\gamma \mathrm{HCD}$ is a rare entity with less than 200 reports in the literature and the majority of cases was diagnosed and classified using outdated classification schemes [1]. Last, the WHO 2008 classification is conflicted as $\gamma \mathrm{HCD}$ is classified as both a variant of LPL and as a distinct disorder [27].

\subsection{Protein Findings}

Monoclonal spike on serum protein electrophoresis was present in $19 / 23(83 \%)$ in one series [9] and 12/28 (40\%) in one literature review [4]. The presence of $\gamma$-heavy chain is documented in the serum of all 23/23 (100\%) patients in one series [9] in 16/16 (100\%) of cases in another [4] and 13/13 (100\%) in another [1] by immunofixation. Median serum IgG level was reported as $1940 \mathrm{mg} / \mathrm{dL}$ (range $462-5280 \mathrm{mg} / \mathrm{dL}$ ) in one series [9] and less than $1 \mathrm{~g} / \mathrm{dL}$ (range $<0.5 \mathrm{~g}-20 \mathrm{~g} / \mathrm{dL}$ ) in another [4]. M-spike in the urine was present in 19/23 (83\%) of patients in one series [9].

\subsection{Bone Marrow Findings}

Marrow involvement is common and morphologically described as a lymphoplasma cell proliferative process [4] [9]. Some reports of increased plasma cells [4], CLL [4], mast cells [28]. One series reported having 7/23 (32\%) patients having marrow involvement [9] another 10/16 (63\%) [4]. In previous series, bone marrow involvement was reported in $58 \%-63 \%$ of cases [4].

\subsection{Histopathology Findings}

$\gamma \mathrm{HCD}$ has no specific histological pattern [4] and there is a great diversity with lymphoplasmacytic proliferation 
being most common [4]. However, $\gamma \mathrm{HCD}$ has been described in association with a plasmacytic process (as in our patient), CLL [4]. Furthermore $\gamma \mathrm{HCD}$ has been reported to arise in the setting of non-Hodgkin lymphoma of various morphologic types, Hodgkin lymphoma, amyloidosis, myelodysplastic syndrome [4] [29] [30].

\subsection{Chromosomal Findings}

Chromosomal abnormalities are uncommon in $\gamma \mathrm{HCD}$ with no frequent abnormality identified [1] [4] [9]. There are isolated reports of trisomy 7 [31], trisomy 3q [1], trisomy 21 [32], complex karyotype [4] and aneuploidy in two cases [33] [34].

\subsection{Immunophenotypic Findings}

Immunophenotypic findings are reported inconsistently in the literature. One recent study by Bieliausjas et al. reported complete Immunophenotypic and molecular cytogenetic analysis on 13 patients [1]. In this series 13/13 (100\%) of patients were CD 20 positive, and 13/13 (100\%) were CD5, CD 10 negative. In this series 6/8 (75\%) tested positive for CD 138 [1]. 9/13 patients were negative for Immunohistochemistry for $\kappa / \lambda(1)$. Clonality by polymerase chain reaction (PCR) performed for IGH was negative in 13/13 (100\%) of cases and PCR for IGK was positive in $(5 / 10) 50 \%$ of cases [1]. Fluorescence in situ hybridization (FISH) for t(IGH), t(MALT), +18q, $\mathrm{t}(\mathrm{BCL} 6)$ in 10/10 (100\%) of cases were negative [1]. FISH for $+3 q$ was positive in $1 / 10(10 \%)$ of cases. It is interesting to note the high degree of CD 20 positivity in this series and there are many cases reported in the literature [1] [4] [9] [10] [35]. This is important since CD 20 positive patients may benefit from immunotherapy with rituximab.

\subsection{Clinical Outcomes}

Given $\gamma \mathrm{HCD}$ is a heterogeneous entity and its clinical course is expected to be quite variable as well. The clinical course can vary from an asymptomatic stable process to an aggressive rapidly progressive malignancy [4]. In some cases $\gamma \mathrm{HCD}$ protein is the only abnormality and no treatment is necessary [4]. In fact, spontaneous disappearance of the $\gamma \mathrm{HCD}$ protein has been documented in several instances [28] [36]. For example, one patient with $\gamma \mathrm{HCD}$ was observed and had stable disease after 134 months follow up [1]. When an underlying malignancy exists, therapy should be directed at the underlying hematologic malignancy and pathologic findings. A wide variety of chemotherapies with or without rituximab have been used successfully including rituximab monotherapy with resolution of adenopathy at 22 month follow up [1], fludarabine and rituximab resulting in partial response (PR) with one cycle [35], second line fludarabine with complete remission (CR) [37], fludarabine, mitoxantrone, dexamethasone (FND) with PR [9], melphalan and prednisone resulting in PR [14], rituximab, etoposide, cyclophosphamide, prednisone, procarbazine resulting in PR [10], sustained CR 20 years with chlorambucil prednisone [9], cyclophosphamide, vincristine, prednisone with PR [9], bortezomib and prednisone with CR [1]. Even autologous stem cell transplant with high dose melphalan has been reported where the patient achieved stable disease after 26 months [38]. In one series where 16/23 patients were treated (14 chemotherapy, 1 splenectomy, 1 thyroidectomy) 6 had CR, 10 had SD. Of the 7 untreated patients 4 had SD, 3 patients died of disease within 15 months. The median survival in this series was 7.4 years [9].

\section{Conclusion}

This case highlights the challenge of correctly recognizing and diagnosing $\gamma \mathrm{HCD}$ which is due to its highly heterogeneous clinicopathologic presentation most common being a lymphoproliferative disorder, autoimmune disease or both. It represents a diagnostic challenge since it arises in the setting of many lymphoproliferative disorders, and the WHO 2008 classification is conflicted as $\gamma \mathrm{HCD}$ is classified as both a variant of LPL and a distinct disorder [27]. Another critical point related to this case is that kappa/lambda staining, the primary mechanism of determining plasma cell clonality, is not useful in exclusively heavy chain disease and can, in such cases, obscure the diagnosis of this malignancy. This is the first reported case of IgG heavy chain disease presenting with PTHrP related hypercalcemia further added to the diagnostic challenge because PTHrp related hypercalcemia is more common in solid tumors and uncommon in hematologic malignancies. Given that skeletal involvement is uncommon in $\gamma \mathrm{HCD}$, hypercalcemia secondary to $\gamma \mathrm{HCD}$ may at times be a PTHrP driven phenomenon; we will recommend that this test be ordered in such cases. Because $\gamma \mathrm{HCD}$ is a heterogeneous entity, the 
choice of therapy should target the underlying entity and pathologic findings. In our case, the etiology of the $\gamma \mathrm{HCD}$ is a plasma cell clone and this is what we target with therapy, with good clinical effect.

\section{Disclaimer}

An abstract for this research was originally published in Blood. Hansra et al. Patient With IgG Heavy Chain Disease Presents with Parathyroid Hormone-Related Peptide Mediated Hypercalcemia. November 15, 2013. Blood $122(21)(1)$ the American Society of Hematology.

\section{References}

[1] Bieliauskas, S., et al. (2012) Gamma Heavy-Chain Disease: Defining the Spectrum of Associated Lymphoproliferative Disorders through Analysis of 13 Cases. The American Journal of Surgical Pathology, 36, 534-543. http://dx.doi.org/10.1097/PAS.0b013e318240590a

[2] Tan, J.N., Kroll, M.H., O’Hara, C.J., Everett, P.C. and Erdogan, E. (2012) Gamma Heavy Chain Disease in a Patient with Underlying Lymphoplasmacytic Lymphoma of the Thyroid. Report of a Case and Comparison with Other Reported Cases with Thyroid Involvement. Clinica Chimica Acta, 413, 1696-1699. http://dx.doi.org/10.1016/j.cca.2012.04.020

[3] Zhang, L., et al. (2013) Unusual Concurrence of T-Cell Large Granular Lymphocytic Leukemia with Franklin Disease Manifested with Massive Splenomegaly. Leuk Lymphoma, 54, 205-208. http://dx.doi.org/10.3109/10428194.2012.697561

[4] Fermand, J.P., Brouet, J.C., Danon, F. and Seligmann, M. (1989) Gamma Heavy Chain "Disease": Heterogeneity of the Clinicopathologic Features. Report of 16 Cases and Review of the Literature. Medicine (Baltimore), 68, 321-335. http://dx.doi.org/10.1097/00005792-198911000-00001

[5] Witzig, T.E. and Wahner-Roedler, D.L. (2002) Heavy Chain Disease. Current Treatment Options in Oncology, 3, 247254. http://dx.doi.org/10.1007/s11864-002-0014-3

[6] Matsubayashi, S., et al. (1985) Extramedullary Plasmacytoma of the Thyroid Gland Producing Gamma Heavy Chain. Endocrinol Jpn, 32, 427-433.

[7] Ottó, S., Péter, I., Végh, S., Juhos, E. and Besznyák, I. (1986) Gamma-Chain Heavy-Chain Disease with Primary Thyroid Plasmacytoma. Archives of Pathology \& Laboratory Medicine, 110, 893-896.

[8] Ockhuizen, T., Jilderda, J.F. and Cazemier, T. (1984) Sequential Development of Waldenström's Macroglobulinemia and Gamma-1-Heavy Chain Disease in a Single Patient. Clinical, Immunochemical, Immunofluorescent and Protein Studies. Acta Haematologica, 71, 53-59. http://dx.doi.org/10.1159/000206510

[9] Wahner-Roedler, D., Witzig, T.E., Loehrer, L.L. and Kyle, R.A. (2003) $\gamma$-Heavy Chain Disease Review of 23 Cases. Medicine, 84, 236-250. http://dx.doi.org/10.1097/01.md.0000085058.63483.7f

[10] Takano, H., Nagata, K., Mikoshiba, M., Nakane, M., Kato, A. and Hamaguchi, H. (2008) Combination of Rituximab and Chemotherapy Showing Anti-Tumor Effect in Gamma Heavy Chain Disease Expressing CD20. American Journal of Hematology, 83, 938-939. http://dx.doi.org/10.1002/ajh.21284

[11] Dickson, J.R., Harth, M., Bell, D.A., Komar, R. and Chodirker, W.B. (1989) Gamma Heavy Chain Disease and Rheumatoid Arthritis. Seminars in Arthritis and Rheumatism, 18, 247-251. http://dx.doi.org/10.1016/0049-0172(89)90045-0

[12] Castelino, D., Gray, F., D’Apice, A., et al. (1994) Primary Sjögren's Syndrome and Gamma Heavy Chain Disease. Pathology, 26, 337-338. http://dx.doi.org/10.1080/00313029400169791

[13] Alexander, M.P., Nasr, S.H., Watson, D.C., Méndez, G.P. and Rennke, H.G. (2011) Renal Crescentic Alpha Heavy Chain Deposition Disease: A Report of 3 Cases and Review of the Literature. American Journal of Kidney Diseases, 58, 621-625.

[14] Oe, Y., Nakaya, I., Yahata, M., Sakuma, T., Sato, H. and Soma, J. (2010) A Case of $\gamma 1$-Heavy Chain Deposition Disease Successfully Treated with Melphalan and Prednisolone Therapy. Internal Medicine, 49, 1411-1415. http://dx.doi.org/10.2169/internalmedicine.49.3499

[15] Moulin, B., et al. (1999) Nodular Glomerulosclerosis with Deposition of Monoclonal Immunoglobulin Heavy Chains Lacking C(H)1. Journal of the American Society of Nephrology, 10, 519-528.

[16] Rott, T., Vizjak, A., Lindic, J., Hvala, A., Perkovic, T. and Cernelc, P. (1998) IgG Heavy-Chain Deposition Disease Affecting Kidney, Skin, and Skeletal Muscle. Nephrology Dialysis Transplantation, 13, 1825-1828. http://dx.doi.org/10.1093/ndt/13.7.1825

[17] Herzenberg, A.M., Lien, J. and Magil, A.B. (1996) Monoclonal Heavy Chain (Immunoglobulin G3) Deposition Disease: Report of a Case. American Journal of Kidney Diseases, 28, 128-131. 
http://dx.doi.org/10.1016/S0272-6386(96)90141-9

[18] Lassoued, K., Picard, C., Danon, F., et al. (1990) Cutaneous Manifestations Associated with Gamma Heavy Chain Disease. Report of an Unusual Case and Review of Literature. Journal of the American Academy of Dermatology, 23, 988-991. http://dx.doi.org/10.1016/S0190-9622(08)80110-7

[19] Papae, R.J., Rosenstein, R.W., Richards, F. and Yesner, R. (1978) Gamma Heavy Chain Disease Seen Initially as Gastric Neoplasm. Archives of Internal Medicine, 138, 1151-1153. http://dx.doi.org/10.1001/archinte.138.7.1151

[20] Faguet, G.B., Barton, B.P., Smith, L.L. and Garver, F.A. (1977) Gamma Heavy Chain Disease: Clinical Aspects and Characterization of a Deleted, Noncovalently Linked Gamma1 Heavy Chain Dimer (BAZ). Blood, 49, 495-505.

[21] Franklin, E.C., Lowenstein, J., Bigelow, B. and Meltzer, M. (1964) Heavy Chain Disease-A New Disorder of Serum $\gamma$-Globulins: Report of the First Case. The American Journal of Medicine, 37, 332-350. http://dx.doi.org/10.1016/0002-9343(64)90191-3

[22] Cooper, D.L., Bolognia, J.L. and Lin, J.T. (1991) Atrophie Blanche in a Patient with Gamma-Heavy-Chain Disease. Archives of Dermatology, 127, 272-273. http://dx.doi.org/10.1001/archderm.1991.01680020144031

[23] Tasca, G., Iorio, R., Basile, U., et al. (2009) Progressive Multifocal Leukoencephalopathy in a Patient with Franklin Disease and Hypogammaglobulinemia. Journal of the Neurological Sciences, 284, 203-204. http://dx.doi.org/10.1016/j.jns.2009.04.035

[24] Yunokawa, K., Hagiyama, Y., Mochizuki, Y., Tanaka, N. and Ochi, M. (2007) Hypertrophic Spinal Pachymeningitis Associated with Heavy-Chain Disease. Journal of Neurosurgery: Spine, 7, 459-462. http://dx.doi.org/10.3171/SPI-07/10/459

[25] Shirakura, T., Kobayashi, Y., Murai, Y., Inoue, T. and Imamura, Y. (1976) A Case of Gamma Heavy Chain Disease Associated with Autoimmune Haemolytic Anaemia: Clinical, Haematological, Immunological and Pathological Details. Scandinavian Journal of Haematology, 16, 387-393. http://dx.doi.org/10.1111/j.1600-0609.1976.tb00332.x

[26] Eisner, S.B. and Mitnick, P.D. (1986) Hypercalcemia and Reversible Renal Failure in Heavy-Chain Disease. Southern Medical Journal, 79, 507-509. http://dx.doi.org/10.1097/00007611-198604000-00030

[27] Swerdlow, S.H., Campo, E., Harris, N.L., et al. (2008) WHO Classification of Tumours of Haematopoietic and Lymphoid Tissues. IARC Press, Lyon.

[28] Van Bergeijk, L., Biewenga, J. and Langenhuijsen, M.M.A.C. (1980) Gamma Heavy Chain Disease with an Unusually Benign Course. Clinical Laboratory Hematology, 2, 83-88.

[29] Yazaki, M., Fushimi, T., Tokuda, T., et al. (2004) A Patient with Severe Renal Amyloidosis Associated with an Immunoglobulin Gamma-Heavy Chain Fragment. American Journal of Kidney Diseases, 43, e23-e28. http://dx.doi.org/10.1053/j.ajkd.2003.12.056

[30] Ellis, V.M., Cowley, D.M., Taylor, K.M. and Marlton, P. (1992) Gamma Heavy Chain Disease Developing in Association with Myelodysplastic Syndrome. British Journal of Haematology, 81, 125-126. http://dx.doi.org/10.1111/j.1365-2141.1992.tb08184.x

[31] O'connor, G.T., Wyant, H.E., Innes, D.J., Normansell, D.E. and Hess, C.E. (1985) Gamma Heavy Chain Disease; Report of a Case with Trisomy of Chromosome 7. Cancer Genetics and Cytogenetics, 15, 1-5. http://dx.doi.org/10.1016/0165-4608(85)90125-6

[32] Gallart, T., Canals, J., Cañadell, E., et al. (1978) A New Case of Gamma-Heavy Chain Disease. Acta Haematologica, 59, 262-276. http://dx.doi.org/10.1159/000207781

[33] Kuroyanagi, T., Kura, K., Akamatau, Y. and Arao, T. (1979) A Case Report of the Immunodysplasia Syndrome and Heavy Chain Disease Associated with Subacute Bacterial Endocarditis. The Tohoku Journal of Experimental Medicine, 128, 325-331. http://dx.doi.org/10.1620/tjem.128.325

[34] Roda, L., David, M.J., Souche, S. and Creyssel, R. (1985) Gamma Heavy Chain Disease DUB: Clinical Immunochemical and Pathological Studies. Haematologica, 70, 115-119.

[35] Inoue, D., Matsushita, A., Kiuchi, M., et al. (2012) Successful Treatment of Gamma-Heavy-Chain Disease with Rituximab and Fludaribine. Acta Haematologica, 128, 139-143. http://dx.doi.org/10.1159/000339097

[36] Wager, O., Rasanen, J.A., Lindeberg, L. and Makala, V. (1969) Two Cases of IgG Heavy-Chain Disease. Acta Pathologica Microbiologica Scandinavica, 75, 350-352.

[37] Agrawal, S., Abboudi, Z., Matutes, E. and Catovsky, D. (1994) First Report of Fludarabine in Gamma-Heavy Chain Disease. British Journal of Haematology, 88, 653-655. http://dx.doi.org/10.1111/j.1365-2141.1994.tb05094.x

[38] Brioli, A., Zamagni, E., Pasquali, S., et al. (2012) Long-Term Follow-Up after Autologous Stem Cell Transplantation for Light- and Heavy-Chain Deposition Disease. Bone Marrow Transplantation, 47, 1248-1249.

http://dx.doi.org/10.1038/bmt.2011.252 